\title{
EL PENSAMIENTO DE JORGE CARPIZO COMO PROGRAMA EN LA AGENDA DE LA EDUCACIÓN Y DE LA SOCIALIZACIÓN DEL JURISTA
}

\section{THE THOUGHT OF JORGE CARPIZO AS A PROGRAM ON THE EDUCATION AGENDA AND THE SOCIALIZATION OF THE JURIST}

\author{
María Leoba CAstañeda Rivas*
}

\begin{abstract}
RESUMEN: En el presente artículo, la autora homenajea a Jorge Carpizo a través de su obra y su preocupación constante por los derechos humanos. Desde La Constitución mexicana de 1917, el universitario emérito centra la relación entre derechos humanos y derecho natural en el marco del positivismo dogmático. Asimismo, se hace énfasis en la perspectiva optimista de Carpizo sobre el reconocimiento de los derechos humanos como camino necesario hacia el perfeccionamiento de los sistemas jurídicos. La autora también exhorta a desarrollar una socialización del jurista que entraña la adquisición de valores y habilidades por parte del individuo. Finalmente se expone el papel de la enseñanza del derecho como medio para combatir los problemas sociales.
\end{abstract}

Palabras Clave: Jorge Carpizo, derechos humanos, derecho natural, socialización, enseñanza del derecho.
ABSTRACT: In this article, the author pays tribute to Jorge Carpizo through his work and his constant concern for human rights. From La Constitución mexicana de 1917, the emeritus focuses the relationship between human rights and natural law under the dogmatic positivism. It also emphasizes Carpizo's optimistic perspective on the recognition of human rights as a necessary path toward perfecting legal systems. Also the author calls the lawyers to develop socialization that involves the acquisition of values and skills by the individual. Finally he discusses the role of legal education as a way to combat social problems.

KEywords: Jorge Carpizo, Human Rights, Natural Law, Socialization, Legal Education.

* Directora de la Facultad de Derecho de la Universidad Nacional Autónoma de México. Primera Directora en 459 años de historia. Doctora en Derecho por la UNAM. Catedrática de Tiempo Completo de la Facultad de Derecho de la UNAM y de la División de Estudios de Posgrado. 
Sumario: I. Los derechos humanos, preocupación central en el pensamiento de Jorge Carpizo. A) Una visión optimista del jurista. II. La socialización del jurista. III. La enseñanza del Derecho. IV. Conclusiones. V. Bibliografía.

I. LOS DERECHOS HUMANOS, PREOCUPACIÓN CENTRAL EN EL PENSAMIENTO DE Jorge CARPIZO

partir de una serie de eventos catastróficos en el plano humanita-
rio, se puede considerar que hubo un notable desarrollo de los de-
rechos humanos; fue la Segunda Guerra Mundial, con sus efectos "colaterales" negativos sobre la población civil y muy especialmente, sobre miembros de minorías étnicas, religiosas o políticas, quienes sufrieron los embates de ideologías totalitarias, un detonador importante.

Si antes de la Segunda Guerra Mundial no se discutía la pertinencia de una teoría jurídica "químicamente" pura, en la cual la reflexión moral y la sociológica estuvieran ausentes o le dieran al menos una mínima consistencia al contenido de las normas (no pensemos en justificación de las mismas), después de los eventos en los cuales se reveló un comportamiento verdaderamente agónico, ${ }^{1}$ el ser humano se encontró en la necesidad de reflexionar sobre esa pertinencia ¿vale la pena, en aras de dotar al estudio del Derecho de un status de cientificidad cercano al de las ciencias naturales (o de las sociales que tomaban como modelo a las propias ciencias naturales) abandonar la tradición humanista cercana a los dos mil quinientos años?

Lo rescatable de los eventos ya referidos fue un favorable proceso de cambio en lo que se puede calificar como los paradigmas del derecho, en torno de la fundamentación de esta disciplina y particularmente, de los derechos humanos.

Hay en la actualidad un paulatino abandono y superación de la idea de concebir el otorgamiento de los derechos humanos, como un acto de gra-

\footnotetext{
${ }^{1}$ Me refiero aquí especialmente al "mito agónico" propio de algunas concepciones del determinismo genético, en las cuales se plantea que el ser humano es egoísta y agresivo por naturaleza y que, por ende, el conflicto y la lucha son inherentes a toda sociedad humana. $C f r$. al respecto: "Teorías agónicas basadas en la violencia", disponible en http://culturadepaz. peternewton.biz/index.php?option=com_content\&view=article\&id=70:teorias-agonicas-basadas-en-la-genetica\&catid=19:naturaleza-humana-esp\&Itemid=37.
} 
cia del Estado, idea fundamental, con la cual fuimos socializadas las viejas generaciones de abogados, y que en su momento se consideró como una verdad irrebatible por lo evidente o aparentemente evidente, dejaba entrever un esquema de autoritarismo que por ser tan propio de la sociedad mexicana todavía de los años setenta y ochenta, no era percibido en toda su magnitud:

Para una sociedad autoritaria, inmersa en la idea de un ogro filantrópico encarnado por el Estado y, en su caso, por el padre de familia, era perfectamente "natural" pensar en que el Estado era quien daba los derechos, ¿si no era él quién más podría hacerlo? la idea de que los derechos humanos debían ser "reconocidos", sonaba por supuesto, a un anquilosado pensamiento religioso que merecía toda la sospecha de los cultivadores de la ciencia jurídica.

En ese contexto de positivismo jurídico radical, Jorge Carpizo, en su señera obra La Constitución mexicana de 1917, navegaba en sentido contrario dispuesto por el pensamiento predominante del Derecho en nuestro país, señaló en 1969: "La noción del Derecho natural está íntimamente ligada a la idea de derechos humanos. Debemos preguntarnos qué es el Derecho natural, y asentar que es un viejo juicio que en su evolución ha recorrido los más diversos matices". 2

Rescata, Jorge Carpizo, una reflexión de dos mil años de tradición cultural en torno de los derechos humanos y plantea, desde ese momento, en un lejano 1969, la relación directa entre los derechos humanos y la concepción del Derecho natural, idea que por supuesto no era grata para los seguidores del positivismo radical.

La fundamentación hecha por Carpizo en la obra referida, está basada en el pensamiento de Jacques Maritain, de quien indica:

El hombre sólo puede realizar su destino dentro de la comunidad social, y esta comunidad no tiene otro fin que servir al hombre. El fin de la comunidad es la realización de una obra en común y la obra en común consiste en que cada hombre viva como persona, es decir, que venciendo las estructuras económicas, tenga tiempo para dedicar al ocio, a sus diversiones y sobre todo a la cultura. El destino del hombre es realizarse como tal, alcanzar su esencia de libertad y cumplir, correctamente, en la medida de sus posibilidades particulares, el trabajo que le ha tocado realizar en su lapso de vida. ${ }^{3}$

${ }^{2}$ CArpizo, Jorge, La Constitución mexicana de 1917, $5^{\mathrm{a}}$ ed., México, IIJ-UNAM, 1982, p. 136.

${ }^{3}$ Ibidem, pp. 135-136. 
Maritain, de quien se ha dicho fue la base para la conformación de la doctrina social cristiana y de la denominada "Democracia cristiana", se preocupa por conformar una "visión integral" del ser humano, en la cual éste no se vea reducido a uno de los aspectos: ni al espiritual solamente ni tampoco al económico: "Maritain hace ver cómo los reduccionistas, que sólo se preocupan y, por lo tanto, se ocupan, de una sola faceta humana, terminan por volverse contra el mismo hombre. Ahogan la riqueza de la diversidad de las manifestaciones humanas, haciendo que también la sociedad pierda riqueza". ${ }^{4}$

Si se supone al ser humano solamente como un zoon politikon, cuya fuente de motivación esencial es lo político o la lucha por el poder, lo cual involucra la dominación sobre los demás o suponerlo exclusivamente como un animal económico y todo lo que conlleva o rodea ese aspecto: ya sea la compulsión de satisfacer las necesidades fundamentales (que tienen que ver con la superviviencia); en ambos casos estamos simplificando en demasía al ser humano, considerado en toda su complejidad, dado que asumimos solamente un aspecto, que ciertamente le corresponde como nota característica a la especia humana, pero que no consitutye, en términos de definición, la "nota esencial".

El ser humano es animal político pero también lo es económico, es social y además es hemernéutico e incluso "videns". Todos estos aspectos, favorables o desfavorables forman parte del ser humano y es justamente lo que no toman en cuenta la mayor parte de las perspectivas reduccionistas, en contra de las cuales se conforma la tesis de Maritain y la del propio Jorge Carpizo. En un período intelectual (e histórico) en el cual se entronizaba a la norma y al Estado como origen o fuente primordial de la norma (al menos en los sistemas jurídicos que tenían una clara orientación iuspositivista), Carpizo apoyado en uno de los pensadores contemporáneos del Derecho natural, se atreve a manifestar la importancia del ser humano, como centro del sistema jurídico.

Esto configura una visión integral. Más allá de la perspectiva que nos pudiera ofrecer el formalismo radical, donde el ser humano es visto solamente como un centro de imputación de derechos y deberes; sin tener en cuenta otros elementos que conforma la entidad "ser humano".

\footnotetext{
${ }^{4}$ Navarra Daniles, Vilma y Paukner Nogués, Fraño, "El proyecto social de Jacques Maritain", en A parte rei. Revista de Filosofia, núm. 33, consultada en: http://serbal.pntic.mec. es/ cmunoz11/maritain33.pdf, el 10 de septiembre del 2012.
} 
Desenvolvimiento decisivo para la idea del Derecho natural es la teoría estoica, donde el logos (divinidad de la stoa) todo lo infunde y determina, tanto en el campo racional como en el irracional. El logos, razón universal, dice qué es lo que se puede hacer, y qué no. Todos los entes, incluso el hombre, participan en el logos (panteísmo), por lo cual las normas que emanan de este principio son universales y eternas. ${ }^{5}$

La referencia a los valores o a una justificación de carácter esencialista no se quedaba en la tradición griega. Sin mayor problema, el jurista en ciernes se apoyaba en autores de la tradición cristiana:

El obispo de Hipona distinguió entre ley eterna, natural y humana. Estas tres leyes -cual pirámide kelseniana $-{ }^{6}$ están entrelazadas entre más a menos y toman su contenido y validez una de otra. La ley eterna es la voluntad divina que ordena y dirige todo el universo. Es la ley universal e inmutable. La ley natural es la ley eterna que ha sido grabada en la mente humana. No son la misma sino - metáfora elegante- que la ley eterna es una especie de sello grabador y la ley natural el sello grabado en la cera. La ley humana se desprende de las dos anteriores leyes, y sólo es obligatoria en cuanto esté de acuerdo con sus progenitoras. Esta tesis revolucionaria, puesto que permite violar la ley humana o temporal, si es contraria a la natural, ni que hablar de la eterna. Santo Tomás en líneas generales siguió el pensamiento del autor de Las Confesiones. Lo importante es que se tiene la idea de una serie de principios que preponderan sobre la ley humana, y ésta no puede violarlos. ${ }^{7}$

Reitero, en un momento en el cual era indiscutible la preminencia de un Estado, de un gobierno que estaba tratando de engullirse a la sociedad, de contenerla en un esquema corporativista, copiado casi de manera acrítica, pero bastante funcional, de los regímenes autoritarios de los años treintacuarenta (la Alemania nazi, la Italia fascista y por supuesto la España franquista), y en el cual nadie discutía que era el gobierno y más especialmente el partido dominante el que pródigamente otorgaba los derechos a los ciudadanos y que en tal virtud éstos debían, en ocasiones soportar el autoritarismo. En esas circunstancias en las cuales todavía era bastante redituable ser

\footnotetext{
${ }^{5}$ CARPIZO, J., op. cit., p. $137 .$.

${ }^{6}$ El subrayado es mío.

${ }^{7}$ CARPizo, J., op. cit., pp. 137-138.
} 
un intelectual orgánico, ${ }^{8}$ Carpizo se decantó por la crítica y por una posición a contracorriente, que no podía ser identificada simplemente como un "iusnaturalismo trasnochado", se vislumbraba en todo caso, la vocación crítica que caracterizó a su obra intelectual.

Remata su exposición de los pensadores iusnaturalistas con los racionalistas de la corriente:

Pufendorf creyó que la razón era el instrumento por medio del cual se podía deducir la ley natural, y que se lograba a través de la contemplación de la naturaleza humana. La base de su especulación es que el hombre necesita vivir en sociedad, ya que Dios le ha concedido una naturaleza social. Pufendorf escribió que los fundamentos del Derecho natural eran: amar a Dios y al prójimo.

Para Wolf, el Derecho natural está determinado por el perfeccionamiento del hombre y de la sociedad (ideas ya apuntadas anteriormente por Leibniz), de lo que se deduce que el postulado principal del Derecho natural es aquel que ordena a los hombres realizar las obras que tienden a su perfeccionamiento, y alejarse de aquellas que lo separan de él, pero el Derecho natural, también, nos compele a tratar de lograr -en cuanto podamos- el perfeccionamiento de los demás. $^{9}$

Si bien es cierto, y es justo aclararlo, que el pensamiento iusnaturalista o que hacía referencia a la importancia de tomar en cuenta aspectos de carácter moral o ético, como parte de las reflexiones en torno del Derecho, no había sido liquidado en el contex to de la doctrina nacional, especialmente de la reflexión iusfilosófica, quizá los casos más significativos de esa tendencia eran entre otros juristas nacionales: Luis Recaséns Siches y Rafael Preciado Hernández. Estamos refiriéndonos, en todo caso, a juristas "de la vieja guardia", en quienes se podría pensar que era "justificado" su pensamiento; sin embargo, en el caso de Jorge Carpizo, lo relevante es que se trataba, en 1969, de uno de los juristas de las nuevas generaciones, de quien podría

\footnotetext{
${ }^{8}$ Me refiero con este término a la función que Gramsci atribuye al intelectual en las modernas sociedades capitalistas:"Los intelectuales son también los portadores de la función hegemónica que ejerce la clase dominante en la sociedad civil. Trabajan en las diferentes organizaciones culturales (sistema escolar, organismos de difusión -periódicos, revistas, radio, cine- etc.) y en los partidos de la clase dominante, con el fin de asegurar el consentimiento pasivo, sino el activo, de las clases dominadas en la dirección que la clase dominante imprime a la sociedad." tomado de:Gramsci, Antonio, El intelectual orgánico, en http://es.scribd.com/doc/7281701/Antonio-Gramsci-El-Intelectual-Organico

${ }^{9}$ Carpizo, J., op. cit., p. 139.
} 
haberse pensado, suscribiría las ideas predominantes del positivismo filosófico. No fue así, la formación académica de Jorge Carpizo significó una evolución iusfilosófica, que respalda ideológico y teóricamente las normas y los productos más importantes de lo jurídico.

Encontramos en estos pensadores (de Recasens a Carpizo) la preocupación constante por centrar la justificación final del Derecho en torno del ser humano, pensado como entidad individual, que es concreta y como entidad social y quizá más allá, como en una entidad abstracta que orienta o debería orientar al proceso de conversión del ser humano. ${ }^{10}$

Concluye Carpizo su argumentación sobre el fundamento iusnaturalista de los derechos humanos, en su señero texto de La Constitución mexicana de 1917, con el siguiente cuestionamiento: "¿Adónde nos ha conducido la exposición sintética y rápida de la evolución del Derecho natural? ¿Cuál ha sido la razón de la importancia que le hemos concedido al tema para abrir este paréntesis en la exposición de los derecho humanos?" y su respuesta es:

Consideramos que encima del Derecho positivo sí existe una serie de principios inviolables. Estos principios son la idea de libertad, dignidad e igualdad, principios que históricamente se han conquistado y que son parte preciosa del acervo cultural humano. Principios universales porque la historia de los pueblos coincide en su lucha por hacerlos objetivos. Libertad, dignidad e igualdad de los hombres como principios superiores contra los cuales no puede ir ningún ordenamiento jurídico, y ellos conforman y determinan una serie de derechos que según la nación y la época se manifiestan en derechos humanos. Pero, como todo hombre por el hecho de ser hombre, porque ha sido la causa por la cual peleó el hombre en contra del opresor, y murieron millones de hombres; todo ser humano, ya sin importar ni el lugar ni el tiempo, tiene derecho a exigir respeto por su calidad de hombre y ciudadano del mundo. Por esto la idea de los derechos humanos se internacionaliza.

Los derechos humanos se plasman porque el hombre sintiendo su esencia de ser libre luchó por ella, y ganó. Porque el hombre quiere vivir, y vivir, como tanto ha afirmado, y ya hemos dicho, no quiere decir vivir una existencia bio-

${ }^{10}$ El término "conversión del ser humano" alude a ese proceso de transformación del homo sapiens sapiens en un auténtico ser humano, esto es, se pasa de ser un simple miembro de la especie de homo sapiens a convertirse verdaderamente en un miembro de la sociedad humana en términos generales y en un miembro de una sociedad concreta, en el inter, el sujeto al socializarse se va individualizando, esto es, se asume de manera muy especial, "personal" si es dable señalarlo 
lógica, sino vivir humanamente, con dignidad, con un mínimo de derechos asegurados frente al Estado y a la economía. ${ }^{11}$

Se propone una solución de continuidad de los derechos humanos, en el pensamiento de Jorge Carpizo. Ello permite suponer que la idea de los derechos humanos es una conquista de la humanidad, en términos generales. Ese privilegio lo ha ganado la humanidad entera en razón de las víctimas que cayeron en las luchas contra la opresión, ${ }^{12}$ por oponerse a los privilegios de los regímenes autoritarios que niegan, casi por principio, la importancia de la dignidad humana como fundamento de las relaciones interpersonales, en especial de aquellas en las cuales hay tal desigualdad material que obliga, de acuerdo con el principio aristotélico, a tratar "igual a los iguales y desigual a los desiguales". ${ }^{13}$

Esta actitud teórico ideológica abona a favor de un pensamiento humanista y por supuesto de un programa educativo que será abordado más tarde, en un inciso especial. Señala el jurista universitario:

El problema actual en lo referente a los derechos humanos es que en su movimiento de tesis, antítesis y síntesis, están llegando a la síntesis, que por naturaleza intrínseca son derechos y obligaciones, sin que se pueda separar nítidamente la obligación del derecho. La antítesis a esta síntesis, es imposible predecirla, pero en el momento actual el cambio lleva la idea de que todo derecho, como toda obligación, no pueden referirse al hombre como ser aislado, sino como sujeto de una función social, y que las declaraciones de libertad, igualdad y dignidad son aseguradas por la libertad, la igualdad y la dignidad.

Los derechos humanos son el estandarte primordial de la felicidad humana;y todo hombre debe estar decidido a luchar por la plena realización de todos y cada uno de estos derechos, otorgados constitucionalmente como garantías. ${ }^{14}$

En esta época, más que en cualquier otro momento de la historia de la humanidad, el ser puede ser concebido como un fin en sí mismo, a pesar de todos los factores que operen en contra de esta idea. Esta coyuntura es presentada por el jurista Jorge Carpizo y ciertamente conlleva un pensamiento y una actitud muy optimista respecto del ser y de la especie humana.

${ }^{11}$ CARPIZO, J., op., cit., p 140.

${ }^{12}$ Idem.

${ }^{13}$ Cfr. Aristóteles, Ética a Nicómaco, Libro v, cap. III, "De la justicia que consiste en los repartimientos", disponible en: http://www.uruguaypiensa.org.uy/imgnoticias/650.pdf.

${ }^{14}$ Ibidem, p. 162. 


\section{A) Una visión optimista del jurista}

Un aspecto del pensamiento de Jorge Carpizo se aborda en este estudio para que el lector reflexione y se pueda concluir algo. Se trata del supuesto debate en torno al cual puede asumirse una posición frente a la vida, frente a la sociedad y sobre todo, ante los retos impuestos por la historia al ser humano en lo individual, como parte de un grupo y finalmente como integrante de una sociedad.

Hay al respecto, tres posibilidades: una, sumergirse en el espejismo del objetivismo, suponiendo que el pensador que se desenvuelve en la historia es capaz de asumir frente a ella, un papel de simple observador; que puede describirla simple y llanamente, sin pasión, sin tomar partido por ninguno de los bandos en pugna, y cuya contradicción le da sentido al proceso de cambio social, y digo que ello es ilusorio, especialmente en el caso de profesionales, cuyas actividades potencialmente pueden incidir de manera directa en el propio curso de la historia, como es por supuesto, el caso de un jurista que incursiona en diversos ámbitos, incluyendo la docencia, la investigación, la administración universitaria y la administración pública.

Las otras dos posibilidades se refieren; una, a mirar con pesimismo a la historia, al acontecer de los hechos y lamentarse constantemente de ello, suponiendo que de nada sirve la acción individual, ni la de los grupos o los grandes movimientos sociales o de masas, que todo y a pesar de todo significará siempre redundar la naturaleza humana que significa repetir los mismos errores y, en su caso, los mismos horrores.

Una variante de esta actitud la constituye, por supuesto, pensar que el curso de la historia es un caos, una indeterminación absoluta donde lo único constante es la sucesión de catastróficos acontecimientos que derrumban a las civilizaciones enteras.

En esta posibilidad (y en su variante del "caos") el papel del Derecho y del jurista en la sociedad es irrelevante. A pesar de los esfuerzos del Derecho como conjunto, como fruto de la sociedad y en muchas ocasiones de un esfuerzo racional o de los juristas, ya sea considerados también en su conjunto o como individuos excepcionales que se oponen a las tendencias de la historia y que, en ocasiones, logran cambios favorables, todo seguirá igual: el ser humano se pierde en la inercia del caos y todo esfuerzo no solamente será inútil, sino además, rápidamente olvidado.

La última de las posibilidades es tratar de ser optimista, ver, o en su caso, tratar de encontrar en los acontecimientos aparentemente caóticos de la his- 
toria de un país o de las naciones en su conjunto, alguna constante o alguna tendencia hacia el perfeccionamiento de las sociedades y del propio ser humano.

Esta actitud favorece la intervención del jurista y la relevancia del Derecho. Se reconoce la importancia de la acción humana, de la actividad y del compromiso personal del individuo, de tal manera que una persona, bajo determinadas circunstancias, puede hacer la diferencia frente a tendencias que pueden ser considerarse como desfavorables, para todo un grupo social.

Esta es la actitud asumida por Jorge Carpizo, y una de las enseñanzas, que bien podrían ser socializadas, en el seno de la comunidad universitaria y muy especialmente en el contexto de la enseñanza del Derecho: frente a una cotidianidad en la cual el contenido de la norma se encamina en una dirección y la realidad social va en dirección contraria, es importante decidir qué se va a hacer, las alternativas son:

a) Desentenderse de esa cuestión y sacar provecho profesional de la misma, actitud que han tomado durante años muchos abogados postulantes;

b) Decantarse por la realidad social y tratar de ajustar el contenido normativo, independientemente de las características de la realidad;

c) Elegir a la norma y empeñarse en ella, aunque la realidad social sea notoriamente diferente, esperando en que "en algún momento la realidad decida ajustarse" (por sí misma) al contenido normativo.

d) Hacer interactuar ambos, de tal manera que se pueda modificar lo modificable en la realidad para que se acerque a la descripción normativa y en su caso, modificar la norma para que se acerque a la realidad social.

Como teórico del Derecho, quizá en la faceta de docente alejado de la práctica profesional, la opción c) y d) son las ideales. Es la actitud (en el caso d), asumida en muchas ocasiones por algunos positivistas radicales, que independientemente de lo dispuesto en la realidad social, enseñan a sus alumnos lo indicado en las leyes y demás disposiciones normativas sin dar espacio a la crítica o a la autocrítica dado que, esgrimen, "es la ley"; y ésta ordena, no discute. Sin embargo, como teórico del Derecho preocupado por la relación con la realidad y además por el contenido de aquello que se va a abrir y enseñar a las nuevas generaciones de abogados, la mejor actitud es la d). 
En el pensamiento de Jorge Carpizo hay una perspectiva muy optimista en relación de los derechos humanos, esto es, el perfeccionamiento de los sistemas jurídicos del mundo, implica una tendencia a reconocerlos derechos humanos en todas las sociedades y en todas las legislaciones, lo cual, por supuesto, no ha sido suficiente.

Hay por supuesto elementos fácticos que podrían oponerse a este optimismo ontológico y casi epistemológico, y de ello dan cuenta innumerables acontecimientos dados en la realidad social del mundo, hechos que reiteradamente repiten muchos de los actos criminales, cometidos durante la Segunda Guerra Mundial y que dieron como consecuencia (a partir de una reacción social negativa) la consolidación de una sociedad mundial (la Organización de las Naciones Unidas), el Juicio de Nuremberg (castigo a los principales responsables de los crímenes en contra de la humanidad, sin el hecho de poder argüir válidamente el "cumplimiento de un deber", en el caso de que los responsables pertenecieran a la milicia) y la creación de tribunales permanentes que tuvieran la oportunidad de juzgar los crímenes de guerra o contra la humanidad que se cometieran en el futuro.

Luego del trauma que debió haber significado en la conciencia humana (imaginemos por un instante la posibilidad de que pudiera existir una conciencia universal con un mínimo de contenidos aceptados por todos los grupos humanos).

Esto se encuentra ligado con la idea de Norberto Bobbio, respecto de la importancia que tiene, no solamente implementar los derechos humanos en las diversas sociedades del mundo, sino además, el mayor reto está constituido por su eficaz implementación en el seno de la sociedad, decía el jurista italiano:

Lo verdaderamente significativo para los derechos humanos no (es) tanto el tema de su fundamentación, que sin duda considera importante, sino el de su real protección, comprometiendo a la comunidad internacional y a los gobiernos estatales a crear todos aquellos mecanismos a través de los cuales se asegure realmente la vigencia de estos derechos. ${ }^{15}$

La educación juega un papel fundamental en ese proceso de lograr que el respeto de los derechos humanos sea efectivo. Aunque hablar de educación

${ }^{15}$ BobBio, N. "Sul fondamentli dei diritti dell'uomo", citado por Javier Saldaña en La dignidad de la persona, fundamento del derecho a no ser discriminado injustamente, p. 58, Disponible en: http://biblio.juridicas.unam.mx/libros/5/2312/8.pdf. 
de una manera abstracta implica simplemente diferir el problema de la eficacia, especialmente si no dotamos de un significado y un contenido concreto a la educación.

Asumimos, por lo tanto, una visión lo suficientemente restringida y orientada de la educación, la cual puede pecar de optimista, pero de un optimismo fundamentado en la acción y en la posibilidad real de cambio, en el potencial de cambio que tiene el ser humano como individuo y como parte de un grupo social que interactúa con otros.

Este optimismo se refleja en la forma en que Carpizo interpreta la evolución del sistema jurídico nacional y que se materializó en una cátedra magistral:

La historia de México tiene, de acuerdo con una postura del jurista citado, un hilo conductor bien definido, que es la defensa y protección de los derechos humanos, aunque en su momento lo reconoció, en la conferencia dictada en su casa, la Facultad de Derecho con motivo de la celebración del Bicentenario de la Independencia y Centenario del inicio de la Revolución Mexicana, que en la actualidad, ese 2010, no estaba en una de sus mejores épocas. ${ }^{16}$

Lo que otros historiadores y pensadores ven de una manera muy crítica, en ocasiones rayando en la autoflagelación cultural como un movimiento casi sin sentido, sin dirección, que solamente significó enormes pérdidas materiales y humanas para el país: la lucha por la independencia. Carpizo lo observa como un movimiento cuya tendencia observable e identificable es el inicio de la lucha por los derechos humanos, lo cual en el caso de Hidalgo se materializa en los decretos por medio de los cuales declara la abolición de la esclavitud, en ellos "se encuentra la idea de los derechos humanos y de la dignidad humana". ${ }^{17}$

Una tendencia similar observa en el movimiento encabezado por Morelos, cuando mueren Hidalgo y los iniciadores, particularmente cuando proclama Los sentimientos de la Nación. Resalta el punto décimo segundo donde se indica que "todos los hombres deben de llevar una vida en correspondencia a su dignidad y para esto hay que aumentar el jornal de pobre, hay que moderar la opulencia...". ${ }^{18}$

\footnotetext{
${ }^{16}$ CARpizo, J., Los derechos humanos en la Independencia y en la Revolución Mexicana, México, Facultad de Derecho-UNAM, Serie Estudios Jurídicos, núm. 76, 2010, p.

${ }^{17}$ Ibidem, p. 8.

${ }^{18}$ Ibidem, p. 9.
} 
Esta interpretación de la historia y del desarrollo jurídico y constitucional que plantea Jorge Carpizo no niega los retrocesos que hubo en la historia de nuestro país, como el periodo de los primeros cincuenta años de vida independiente, durante los cuales cualquier indicio de derechos humanos manifestados en las normas era violado en una realidad social convulsionada por las luchas entre las diversas facciones.

Concluye su conferencia el doctor Carpizo, con un programa:

...tenemos una gran deuda: hacer que los derechos humanos en México sean una realidad y así, honraremos a la generación de la Independencia y a la generación de la Revolución Mexicana. ${ }^{19}$

El doctor Carpizo ratifica su visión muy centrada de la realidad nacional, a pesar de su optimismo, señala en una obra, en la que participa hacia 2008, lo siguiente:

Bien sabido es que las instituciones las hacen funcionar y las actualizan las personas, estas son la sangre y la energía de aquéllas. Las instituciones correctamente estructuradas no funcionan adecuadamente si en los cargos directivos no se encuentran las personas idóneas. Cuando los servidores públicos son incompetentes, irresponsables, no comprometidos con su labor o corruptos, o una combinación de algunos o de todos estos aspectos, las mejores instituciones se encaminan ineluctablemente al fracaso, el cual puede ser de proporciones mayores, si además se aúnan estructuradas mal o débilmente concebidas. ${ }^{20}$

A este panorama un tanto crudo de la realidad nacional, Carpizo le atribuía cuatro factores que complicaban aún más la situación y que de hecho a poco menos de un año de su muerte agudizan esa situación:

La situación anterior resulta más grave si se inscribe en un clima social de desprecio a la ley, de tolerancia a la corrupción, de pérdida de valores morales laicos y de mentiras. ${ }^{21}$

De estos cuatro factores mencionados por el jurista universitario, en todos tiene una intervención muy importante la educación, concretamente la

${ }^{19}$ Ibidem, p. 32.

${ }^{20}$ Carpizo, Jorge, "La moral pública en México", en Carpizo, Jorge. Gómez Gallardo, P.,y Villanueva, E., Moral y libertad de expresión, México, Jus-Benemérita Universidad de Puebla-Libertad de Expresión, 2008, p. 11.

${ }^{21}$ Idem. 
educación formal, aunque por supuesto la parte informal puede ayudar a reforzar los contenidos que se dan en la escuela, tal y como se abundará brevemente más adelante.

\section{LA SOCIALIZACIÓN DEL JURISTA}

Es un tema poco explorado por lo general en los estudios hechos en torno de la carrera del licenciado en Derecho. La mayor parte de las instituciones educativas se preocupan, incluyendo por supuesto a la nuestra, en los contenidos curriculares y en la estructura de las materias, en mantener en constante actualización los temarios, en concordancia con los cambios que sufre el Derecho positivo, pero no se ocupan de fenómenos considerados ajenos al interés de los márgenes de la ciencia jurídica dogmática. Esto era lo frecuente y lo válido en los estudios y en las instituciones de educación superior, hasta hace algunos años; sin embargo, a partir del nuevo milenio, con los retos de hoy, en el proceso de mundialización es muy probable que se deban cuestionar y replantear los esquemas que se consideraban válidos, y entonces se deberá dirigir la mirada hacia otros procesos y fenómenos que usualmente se consideran propios de disciplinas como la teoría pedagógica, la psicología social y la sociología general o la sociología educativa.

Damos por sentado que quienes ingresan a las escuelas del nivel superior, son seres humanos formados de manera sólida en su casa y en los niveles previos de educación. Esta idea ha merecido tantas evidencias en contra, que en la actualidad, la actitud de las autoridades educativas, responsables en última instancia de los seres humanos que egresan de sus instituciones con la idea de ser los operadores del Derecho, ha sido confiar en la formación previa que han tenido sus alumnos, esto deriva en una ausencia total de énfasis en aspectos de carácter remedial en los casos que corresponda (por ejemplo, implementar cursos adicionales de expresión oral o expresión escrita y en el mejor de los casos, de metodología de la investigación documental).

La socialización entraña dos elementos, uno favorable, consistente en la asimilación de los valores y principios que permiten a un individuo actuar en el contexto de un grupo, en este caso, de profesionales que se encargan de operar con las normas jurídicas; y otra, desfavorable, la adquisición, en el mismo proceso, de un conjunto de actitudes y desarrollo de habilidades y de una "forma de ser" de ese conjunto, o de una porción de ese conjunto 
de profesionales que en ocasiones (aludiendo a la teoría de los paradigmas de Thomas S. Kuhn), construyen los modelos teóricos durante la etapa de la "ciencia normal"; esto es, no solamente se da la enseñanza de los modelos en sí, sino también el traspaso de los problemas, de las preguntas fundamentales en torno de un aspecto del universo y además, modos de investigar y de abordar los problemas y los temas... hay ocasiones incluso, que se transmiten prejuicios.

Esto se puede observar muy claramente en la socialización formal del conocimiento jurídico: los profesores no solamente transmiten el conocimiento en torno del contenido de las normas y la manera de operarlas, ya sea de acuerdo con lo que indican las propias normas sino también, con base en lo que ocurre en la realidad.

Transmiten también la ideología dominante en un tiempo y lugar determinados, el paradigma que se constituyó en un período de "ciencia normal" o en su caso, transmiten también los prejuicios que predominan en una práctica profesional determinada.

Poco conscientes de estas dinámicas sociales, los profesores de escuelas de derecho, nos dedicamos a transmitir "todo el paquete cognitivo", en muchas ocasiones, sin darle una mirada crítica a nuestras propuestas, en las cuales, como se ha señalado, suelen transmitirse adicionalmente prejuicios y dogmas.

El alumno egresado, si tiene la suerte de estudiar más allá de la licenciatura; o si su mirada crítica es suficientemente aguda para darse cuenta de ese hecho, puede superar estos elementos y hacer integral su formación.

La socialización es un proceso que se desarrolla de manera consciente y esto ha sido explorado de manera tradicional por la literatura sociológica y de la psicología social, pero también hay pautas que se trasmiten de manera inconsciente, las cuales, por supuesto pueden ser motivo de un proceso de reflexión personal o de compartir las experiencias personales de manera intersubjetiva, partimos por supuesto de suponer que la socialización es:

(El) conjunto de los procesos mediante a través de los cuales, un individuo desarrolla a lo largo de todo el arco de la vida, en el curso de la interacción social con un número indefinido de colectividades, generalmente a partir de la familia o de una organización que la sustituye en los primeros años de vida, cuando el niño es física y psíquicamente dependiente de otros, el grado mínimo, y en ciertas condiciones grados cada vez más elevados, de competencia comunica- 
tiva (...) compatible con las exigencias de su supervivencia psicofísica dentro de una determinada cultura y en un determinado nivel de civilización $(\ldots .)^{22}$

La socialización, al insertar paulatinamente al ser humano en la sociedad y convertirlo en un auténtico individuo, en la medida en que internaliza de manera diferenciada los valores del grupo, sus opiniones y sus intereses, entre otros elementos.

Por extensión, suele entenderse por socialización también el resultado o producto de dichos procesos, bajo formas de rasgos caracteriales, actitudes, procesos, disposiciones de la necesidad. Queriendo acentuar la interiorización de los elementos culturales que ocurre en los primero años de vida $(\ldots.){ }^{23}$

Concluye el propio Luciano Gallino que la socialización implica "tranformar al genotipo en fenotipo social".

En la Facultad de Derecho, estamos apoyando la socialización consciente de las nuevas generaciones y el primer paso fue dado en la bienvenida a los alumnos que ingresan a la carrera, con el involucramiento de los padres de familia, detectamos, que una proporción muy importante de nuestros alumnos, son todavía hijos de familia, apoyados de manera consistente por sus padres, ${ }^{24}$ de tal forma que se involucró a los padres de familia en un acto solemne en el cual se tomó protesta a los alumnos de nuevo ingreso, quienes se comprometen formalmente a dar su mejor esfuerzo en el contexto de los estudios del Derecho.

Mas allá del ritualismo de ese acto, hemos querido dotarlo de una sentido de inserción social consciente, a partir del cual, los alumnos de nuevo ingreso, toman plena consciencia de que ingresan al mundo de los licenciados en Derecho, y que éste es, o al menos se trata de concebir, con la ayuda de todos los docentes, que asuman la propuesta; el mejor de los mundos posibles, tanto para los futuros abogados, como para sus familias y para la sociedad en general.

${ }^{22}$ Gallino, Luciano, "Socialización”, en Diccionario de Sociología, trad. de Stella Mastrangelo y Lorenzo Alegría, $3^{a}$ ed., México, Siglo xxi, 2005, p. 799

${ }^{23}$ Idem.

${ }^{24}$ Cfr. Al respecto Perfil de aspirantes y asignados a bachillerato y licenciatura de la UNAM 2010-2011, México, Secretaría Administrativa, Dirección General de Planeación, UNAM, 2011, p. 47. Versión electrónica disponible en: http://www.planeacion.unam.mx/ Publicaciones/pdf/perfiles/aspirantes/asp2010-2011.pdf 
Esto forma parte de una "tendencia" observable en el Derecho, que ha pasado de un paradigma de individualismo, en ocasiones interpretable como "excesivo", propio de las etapas tempranas del liberalismo o de las tendencias actuales del neoliberalismo radical o "turbocapitalismo" a unas versiones "moderadas", especialmente durante la etapa de la socialización del Derecho.

\section{LA ENSEÑANZA DEL DERECHO}

Dado que en el proceso de socialización se abordó brevemente el aspecto no formal de la enseñanza, en este inciso se revisará especialmente el aspecto de carácter formal. Esto involucra, por supuesto, los planes y programas de estudio de la Licenciatura en Derecho.

Se mencionaron anteriormente cuatro de los grandes factores que Jorge Carpizo mencionaba como elementos que podrían agudizar los problemas sociales descritos (cfr. Supra p. 13), respecto de los mismos se indicó que la educación podía significar un factor muy importante para su solución. Se indicará a continuación, en particular, el papel que puede jugar la enseñanza del Derecho en el nivel profesional y que puede ser asumido por la propia Facultad de Derecho.

a) El desprecio a la ley, y a todos los productos del Derecho en general puede combatirse con una razonada y reflexionada enseñanza de las normas, no solamente en el nivel profesional que nos ocupa a muchos como plan de vida y como forma de ganarnos la vida, sino debería ser extensiva a otros niveles educativos, por lo menos los inmediatos (el nivel medio superior y la secundaria). Esto implicaría por supuesto que la influencia de las facultades de Derecho pudiera trascender más allá de los muros de sus aulas y pudiera impactar, vía la divulgación de la cultura jurídica, hacia otros niveles educativos;

b) La tolerancia a la corrupción. La "normalización" es un proceso descrito por la psicología social que consiste en que un grupo social o la sociedad en su conjunto poco a poco va calificando un comportamiento, antes visto como desfavorable o incluso como socialmente peligroso (entendiendo por esto el hecho de que pueda poner en peligro a la es- 
tructura de la sociedad), como una conducta que por su frecuencia deja de representar peligro. ${ }^{25}$

El proceso de normalización ${ }^{26}$ se puede observar en los procesos de aumento de la tolerancia, los cuales por supuesto se consideran como favorables puesto que implican el reconocimiento de la multiculturalidad en las sociedades contemporáneas ${ }^{27}$ y ello implica o debe implicar, mayor tolerancia entre los grupos sociales. Lo que no es favorable es el reconocimiento y aumento de la tolerancia de las conductas que atentan en contra de la dignidad humana, lo cual se traduce en muchas ocasiones en una tendencia hacia el multiculturalismo. ${ }^{28}$

Bajo ese contexto, la educación formal debería favorecer la normalización de las conductas que favorecen el desarrollo humano y desalentar aquellas que atentan contra la dignidad humana y el trato igualitario o equitativohacia los miembros de la sociedad.

La corrupción, por supuesto que es una conducta y una subcultura que no debería ser alentada, bajo ninguna circunstancia en el proceso de enseñanza del Derecho y en propio proceso de socialización de las nuevas generaciones de licenciados en Derecho.

La tolerancia a la corrupción forma parte de un rasgo muy acentuado en la sociedad mexicana (no es privativo de algún sector o grupo social) y es una inercia subcultural contra el cual en muchas ocasiones tiene que lidiar la enseñanza formal del Derecho y tiene que ver por supuesto con

${ }^{25}$ Cfr Al respecto el planteamiento de Maritza Montero sobre los mecanismos que combaten la desviación social: "La desviación social", en SALAZAr, José Miguel et al., Psicología social, México, Trillas, 1984, p. 356.

${ }^{26}$ Cfr. Ibidem, p. 357.

${ }^{27}$ Estamos entendiendo el término en la forma en que lo hace León Olivé: "La multiculturalidad, en general puede ser entendida como el fenómeno que señala la existencia y convivencia de varios grupos culturales en un territorio o en una situación o bien dentro de un mismo Estado. Respecto de este término, León Olivé señala que "en ocasiones el término "multicultural" se utiliza para describir sociedades en donde conviven grupos que provienen de diversas culturas". Cfr. Olivé, L. Interculturalismo y justicia social, citado por HernáNDEZ Reyna, Miriam, "Sobre los sentidos de "multiculturalismo" e "interculturalismo", en $R a$ Ximhai, mayo-agosto, año/vol. 3, núm, 2002, Universidad Autónoma Indígena de México, p. 431. Versión electrónica disponible en: http://redalyc.uaemex.mx/pdf/461/46130212.pdf

${ }^{28}$ Este concepto tiene un sentido "normativo", "expresa un concepto que se refiere a modelos de sociedad que pueden servir como guía para establecer o modificar relaciones sociales, para diseñar y justificar políticas, para tomar decisiones y para realizar acciones". Ibidem p. 432. 
la aparente disyuntiva entre enseñar la realidad o enseñar el deber ser planteado por las normas y por la doctrina jurídica.

c) Tolerancia a la pérdida de valores laicos. Si bien lo deseable no es un regreso a la educación religiosa, que históricamente ha sido fuente, en términos generales, de conflictos ideológicos e incluso armados; si es necesario hacer que la reflexión moral regrese a la escuela, que se retome, tal y como lo manifestaron en su momento Miguel Reale, Eduardo García Máynez y Luis Recasens Siches, la dimensión fundamental valorativa del Derecho.

No deberá seguirse la tendencia, hasta hace algunos años dominante, de la unidimensionalidad del Derecho centrada en el aspecto formal.

d) Tolerancia a la mentira. Aunque parezca un componente de educación religiosa, el combate a la tolerancia de la mentira debe integrarse al programa de formación de las nuevas generaciones. Este pendiente social se ha traducido en el ámbito jurídico en el concepto de la transparencia y de la exigencia de rendición de cuentas especialmente de la actividad y de la gestión de los servidores públicos de frente a la ciudadanía.

Es probable, que dada la gran cantidad de temas incluyentes de los mapas curriculares de la formación en licenciatura, esta idea de introducir elementos adicionales a lo que tradicionalmente es el programa positivista de formación del licenciado en Derecho, resulte excesivo para muchos, la tendencia es por supuesto, a la simplificación de los planes de estudio, lo cual deja fuera las reflexiones filosóficas, éticas y axiológicas. Bajo tal circunstancia, sería interesante determinar cuál es la función que se atribuye y se desea respecto del egresado de la carrera. La posición perseguida en la UNAM es hasta el momento, favorecer una formación integral y lo más completa posible, de tal manera que los componentes éticos sean fundamentales en la formación y en el perfil de los egresados, en tal sentido, preocupaciones como las expresadas por Carpizo siguen siendo muy puntuales y temas de debate y reflexión permanente.

Por lo que respecto a la formación de los formadores, tarea que tradicionalmente ha sido asignada en el posgrado de la Facultad de Derecho, especialmente a través de la Maestría en Derecho, en su vertiente "pedagógica", el énfasis en el estudio e investigación de los procesos de socialización inmersos en el propio proceso de enseñanza-aprendizaje que se lleva a cabo en la Facultad de Derecho, es apenas incipiente en las investigaciones. Una de 
las tareas pendientes y que se han asumido en esta dirección será la promoción de esas investigaciones, que tendrán características de tipo empírico, además por supuesto, de las reflexiones de carácter filosófico o teórico.

Por lo pronto, en el ámbito de la reflexión teórica, hay tesis de maestría que están abordando el aspecto de la relación afectiva en el proceso enseñanza-aprendizaje y que parten de la idea de que en dicho proceso hay algo más que la transmisión de información o la aprehensión por parte de los alumnos.

Hay investigaciones que abordan los aspectos lúdicos que necesariamente, de acuerdo con las nuevas tendencias educativas, deben o deberían estar involucrados en la enseñanza, citando a uno de nuestros grandes maestros eméritos, el doctor Guillermo Floris Margadant: "en este tiempo -y se refería apenas unos cuantos años antes de su muerte- los docentes solamente no nos podemos dar un lujo: el ser aburridos para los alumnos". ${ }^{29}$

Y hay por supuesto, investigaciones realizadas en torno del uso de las tecnologías de la información y la comunicación (TICS) en el proceso educativo, no solamente en lo que podríamos denominar como su uso y apoyo para la clase presencial, sino también en la educación a distancia y en el sistema abierto; ámbitos en los cuales la enseñanza tradicional basada con el modelo de cátedra magistral no resulta suficiente, dadas las exigencias que plantean las nuevas generaciones.

Esto habla de lo que esperemos sea una tendencia en los estudios de posgrado el vincular la práctica docente y la investigación educativa y del proceso enseñanza-aprendizaje, efectuado en los diferentes niveles de la Facultad de Derecho. Durante mucho tiempo, las investigaciones tanto en la licenciatura, cuanto en el posgrado, han abordado, con la ayuda de los especialistas que conforman el claustro de profesores, temas de la más variada índole, tradicionales, propios de las llamadas ciencias jurídicas dogmáticas, hasta los temas que de un tiempo para acá se han considerado como "de frontera" en la investigación jurídica, desde los temas que vinculan al Derecho con descubrimientos en el área de las ciencias y esa inquietante interdisciplina denominada bioética, hasta preocupaciones que tienen un corte más iusfilosófico, en el que supuesto se involucra el estudio de los derechos humanos

${ }^{29}$ Como ejemplo de esta filosofía de vida asumida de manera fervorosa hasta el final de sus días, hay una obra que es intensamente divertida: La sexofobia del clero, Miguel Ángel Porrúa, México, 1999 passím. Esta obra, si bien puede levantar un poco de desasosiego entre las mentalidades conservadoras, puede ser un magnífico ejemplo de obra que reúne a un tiempo las cualidades de ser rigurosa, divertida y sarcástica. 
y de la forma en que pueden hacerse efectivos, ya sea en el ámbito nacional y en el internacional.

Nos falta por supuesto, alentar la investigación en la esfera de la enseñanza de los derechos humanos, por supuesto, estamos, trabajando en ello. Más que honrar a un insigne jurista salido de nuestra institución, del seno de la Facultad de Derecho con la imposición de su nombre, de manera muy justa considero, al edificio del Posgrado de la Facultad, creo que honraremos su memoria alentando la investigación en las áreas de su interés, para tenerlo siempre presente.

\section{CONCLusiones}

A partir de la indagación muy somera y por supuesto superficial de algunos de los trabajos de Jorge Carpizo podemos esbozar al menos las siguientes características de su pensamiento:

- La preocupación por el desarrollo de los derechos humanos, ya sea en su nivel académico o en su aspecto fáctico como funcionario público, fue una de las constantes del pensamiento de Jorge Carpizo. Su visión fue siempre optimista, tenía la idea de que se puede desarrollar y confió en las instituciones, por supuesto con la constante supervisión y apoyo de los seres humanos.

- Su visión es totalmente humanista, más allá de las modas ideológicas y teóricas, Carpizo fue un humanista y con ello recuperó una larguísima tradición del pensamiento jurídico que se vio perturbada por la emergencia del positivismo filosófico y por el positivismo jurídico. Perturbada más no interrumpida, prueba de ello fue el surgimiento de pensadores que cuestionaron el enfoque estrictamente positivista que había predominado, autores de la talla de Rafael Preciado Hernández, Luis Recasens Siches y por supuesto Jorge Carpizo.

- Jorge Carpizo es un pensador optimista, indaga e interpreta los hechos históricos como un proceso del perfeccionamiento del ser humano. En el ámbito de la civilización, puede significar el alejamiento de sus pulsiones que derivan en comportamientos agresivos que pueden significar (y que han significado incluso en la historia reciente) la muerte de millones de seres humanos y la protección de los Derechos humanos. 
- Interpreta de esa manera la historia de nuestro país, el desarrollo de sus instituciones jurídicas y sociales: tienen como tendencia el perfeccionamiento del ser humano a través del reconocimiento de los derechos humanos. Esto no es óbice para que reconozca y puntualice los problemas que existen en la sociedad mexicana y los factores más importantes que influyen en esa problemática.

- Una parte importante del pensamiento de Jorge Carpizo se puede convertir en un programa de acción, que puede partir de un programa en el sentido educativo: la preparación y socialización de las nuevas generaciones en las preocupaciones, problemas y puntos de partida señalados por el jurista universitario.

- La tarea de los operadores del Derecho, de quienes socializan a las nuevas generaciones del Derecho, entre algunos de los cuales podemos encontrar por supuesto a los docentes y a quienes tienen que ver con tareas de divulgación o de difusión científica, asumir el compromiso expresado, como preocupación, en el pensamiento de Jorge Carpizo ¿cómo lograr que los derechos humanos sean eficaces?

- La respuesta, al menos de manera parcial, se encuentra en una debida información y formación en la enseñanza del Derecho. Ideal sería que pudiéramos incidir, como institución, en la formación que se da en los niveles iniciales del conocimiento del Derecho, esto es, en la educación básica, pero ante esa dificultad, estamos comprometidos en el ámbito que nos toca: reitero una idea expresada con anterioridad: estamos trabajando al alentar la investigación en la esfera de la enseñanza de los derechos humanos, por supuesto, esa es la mejor forma de honrar a un insigne jurista salido de nuestra institución, del seno de la Facultad de Derecho.

\section{BiBLIOGRAFÍA}

Carpizo, Jorge, La Constitución mexicana de 1917, $5^{\mathrm{a}}$ ed., México, IIJ UNAM, 1982.

------. "Los derechos humanos en la Independencia y en la Revolución Mexicana”, en Serie Estudios Jurídicos, núm., 76, México, Facultad de Derecho, UNAM 2010. 
------ "La moral pública en México" en Moral y libertad de expresión, Carpizo, Jorge. Gómez Gallardo, Perla y Villanueva, Ernesto (coords) México, Jus-Benemérita Universidad de Puebla-Libertad de Expresión, 2008, p. 11.

Gallino, Luciano, "Socialización”, en Diccionario de Sociología, trad. de Stella Mastrangelo y Lorenzo Alegría, $3^{a}$ ed., México, Siglo XXI Editores, 2005.

GramsCI, Antonio, El intelectual orgánico en http://es.scribd.com/ doc/7281701/Antonio-Gramsci-El-Intelectual-Organico

Margadant, Guillermo, La sexofobia del clero, México, Miguel Ángel Porrúa, 1999.

Perfil de aspirantes y asignados a bachillerato y licenciatura de la UNAM 2010-2011, México, Secretaría Administrativa, Drección General de Planeación, UNAM, 2011. Libro en versión electrónica disponible en: http:// www.planeacion.unam.mx/Publicaciones/pdf/perfiles/aspirantes/asp20102011.pdf

Salazar, José Miguel et al., Psicología social, México, Trillas, 1984.

Artículos disponibles en Internet

Aristóteles, Ética a Nicómaco, Libro v, cap. III "De la justicia que consiste en los repartimientos", disponible en: http://www.uruguaypiensa.org. uy/imgnoticias/650.pdf

CARPIZO, Jorge, "La libertad de expresión frente a la no discriminación", en Revista de la Facultad de Derecho de México, núm. 252, julio diciembre de 2009.

Boвbio, N., "Sul fondamentl dei diritti dell'uomo", citado por Javier Saldaña en La dignidad de la persona, fundamento del derecho a no ser discriminado injustamente, p. 58. Disponible en: http://biblio.juridicas.unam.mx/ libros/5/2312/8.pdf

Navarra Daniles, Vilma y Fraño Paukner, Nogués, "El proyecto social de Jacques Maritain", A parte rei, Revista de Filosofía, núm. 33, consultada en: http://serbal.pntic.mec.es/ cmunoz11/maritain33.pdf,.

"Teorías agónicas basadas en la violencia", disponible en: http://culturadepaz.peternewton.biz/index.php?option $=$ com_content\&view $=$ article\&id $=$ 70:teorias-agonicas-basadas-en-la-genetica\&catid=19:naturaleza-humanaesp\&Itemid=37 
Hernández Reyna, Miriam, "Sobre los sentidos de "multiculturalismo" e "interculturalismo", Ra Ximhai, mayo-agosto, año/vol. 3, núm. 2002, Universidad Autónoma Indígena de México, p. 431, versión electrónica disponible en http://redalyc.uaemex.mx/pdf/461/46130212.pdf 